\title{
PROGRESSO, MODERNIZAÇÃO E SUSTENTABILIDADE: DESAFIOS PARA AS POLÍTICAS AGRÍCOLAS
}

\section{PROGRESS, MODERNIZATION AND SUSTAINABILITY: CHALLENGES TO THE FARMING POLICIES}

Telmo Marcon*

\begin{abstract}
Resumo: O presente texto é resultado de pesquisas bibliográficas já realizadas e discute como o discurso da modernização e do progresso, de modo mais acentuado nas últimas duas décadas, vem conquistando cada vez mais uma posição hegemônica também em relação à agricultura. Nesse movimento, predomina uma perspectiva determinista, segundo a qual não existe qualquer possibilidade alternativa ao modelo dominante que se acha em implantação desde a década de 1950 no contexto da revolução verde, baseado no uso intensivo de produtos químicos. As experiências de produção da subsistência tradicionalmente construídas são desprezadas em nome da modernização e do progresso. Nesse contexto, ganha destaque a exploração intensiva do solo, a destruição de recursos naturais e o uso em larga escala de insumos químicos. Até onde esse modelo sustenta-se? Como ficam as experiências historicamente construídas, desqualificadas como inviáveis? Quais são os riscos desse modelo para as pessoas e para o planeta, ou seja, para o futuro da humanidade?
\end{abstract}

Palavras-chave: Políticas agrícolas. Modernização. Progresso. Sociedade de riscos.

\begin{abstract}
This text based on bibliographic research discusses how the discourse about modernization and progress, especially in the last decades, achieved a hegemonic stand even in relation to agricultural matters. A determinist perspective predominates in this movement, according to which there is no other alternative to the predominant model which has been established since the 1950's in the context of the green revolution based on the intensive use of chemical products. The production experiences of subsistence which had traditionally been built are neglected on behalf of modernization and progress. In this context, the intensive exploitation of the soil, the destruction of natural resources and the excessive use of chemical input stand out. How far does this model sustain itself? What about the historically built experiences that are considered impracticable? What are the risks of this model to people and to the planet, i.e., to the future of humanity?
\end{abstract}

Keywords: Agricultural policies. Modernization. Progress. Risk society.

\footnotetext{
* Doutor pela Pontifícia Universidade Católica de São Paulo e pós-doutor pela Universidade Federal de Santa Catarina. Professor da Universidade de Passo Fundo. E-mail: <telmomarcon@gmail.com>

* Doctor from the Catholic University of São Paulo and postdoctoral from the Federal University of Santa Catarina. Professor at the Passo Fundo University. E-mail: <telmomarcon@gmail.com>
} 


\section{Considerações iniciais}

A pergunta pelo futuro da agricultura não pode deixar de ser feita em cada momento. Por mais que os processos industriais tenham avançado, a agricultura continua uma base fundamental para a produção de alimentos e de matérias-primas. Em que condições a produção agrícola está sendo realizada? Quais as garantias de qualidade? O modelo é sustentável? Quais os riscos inerentes a esse modelo que prima apenas pelo aumento da produção através da modernização dos processos produtivos e do uso intenso de insumos químicos? No artigo "O país dos agrotóxicos”, publicado pelo Jornal Extra Classe do Sinpro/RS, Belmonte (2012, p. 8-9) traz dados alarmantes, entre os quais o de que $o$ Brasil é o maior consumidor de agrotóxicos (inseticidas, fungicidas e herbicidas) do mundo. $\mathrm{O}$ consumo anual é de 1 bilhão de litros, o que equivale a aproximadamente 20 litros por hectare e mais de 5 litros por habitante. Em 2008 o Brasil foi responsável por $16 \%$ do consumo mundial.

O modelo de produção agrícola que, hoje, é hegemônico vem sendo impulsionado desde a década de 1950, no contexto da revolução verde, e apoia-se em conceitos como modernização e progresso. Como esse discurso tem sido elaborado, difundido e incorporado, de modo especial por agricultores, em suas práticas cotidianas? Que compreensão de tempo e de história está subjacente a esses conceitos?

No presente artigo, pretende-se fundamentar uma crítica aos conceitos de modernização e progresso a partir de uma análise da concepção de tempo linear e homogêneo. Dessa concepção, decorre uma visão determinista que interfere profundamente no modelo de agricultura e nas políticas agrícolas. Por ser profundamente sedutor, esse modelo sonega interesses subjacentes e os riscos inerentes para o presente e para o futuro. Para tanto, isto é, para que se proceda à análise dos aspectos postos em pauta, buscam-se fundamentos em autores como Walter Benjamin, Boaventura de Sousa Santos e Ulrich Beck. Dos dois primeiros, recupera-se a crítica à concepção de tempo linear e determinista; de Beck, procuram-se argumentos que ajudam a dimensionar os riscos que estamos vivendo em decorrência das opções que estão sendo feitas. Por fim, serão confrontadas essas reflexões com o modelo hegemônico de agricultura e os desafios que esse quadro coloca.

\section{O tempo linear e determinista e a ne- gação da pluralidade de experiências}

A compreensão de tempo que temos nunca é neutra. Ela pode resultar de uma compreensão que reconheça as múltiplas temporalidades presentes nas complexas relações sociais; pode ser monolítica e linear, privilegiando apenas o futuro. É dentro dessa segunda perspectiva que se fundamenta o modelo hegemônico, apoiado no discurso da modernização e do progresso. Por serem conceitos complexos e ambíguos têm uma aparência progressista e revolucionária. $\mathrm{Na}$ realidade, escondem interesses conservadores. O projeto da "revolução verde" é característico desse processo.

Retirado de um contexto de transformações radicais, de subversão à ordem instituída, o conceito de revolução é apropriado por um projeto conservador que tem como alvo mudanças periféricas, mas não substanciais do papel da agricultura, ou seja, baseia-se na incorporação de novas tecnologias de produção e uso intensivo de insumos químicos visando ao aumento da produção. 
Nesse caso, o conceito de revolução, portanto, está associado ao aumento da produção.

Desde as grandes narrativas mitológicas antigas, existem tensões entre diferentes temporalidades. No século XV, no entanto, fortalece-se uma perspectiva que privilegia uma temporalidade que é a do colonizador europeu, marcada por um tempo "linear e vazio”, como afirma Benjamin (1994), que nega as temporalidades presentes nas práticas dos povos colonizados. Os conquistadores oriundos, especialmente, de Espanha e Portugal reconhecem apenas o tempo de que se dizem portadores e representantes da razão e da civilidade. A superioridade técnica e militar passa a ser exaltada ao mesmo tempo em que os povos colonizados são classificados como atrasados, irracionais, indolentes, canibais etc. A negação de outras temporalidades é condição para a imposição de um único tempo: o tempo da conquista. Como assevera Benjamin, “a idéia de um progresso da humanidade na história é inseparável de sua marcha no interior de um tempo vazio e homogêneo. A crítica da ideia de progresso tem como pressuposto a crítica dessa marcha” (1994, p. 229).

A concepção hegemônica de tempo fundamenta-se numa teleologia segundo a qual a história já tem fins determinados, bastando apenas persegui-los. Sendo assim, a tese do fim da história é expressão dessa concepção de tempo (FUKUYAMA, 1992; ANDERSON, 1992). Dessa forma, nega-se a possibilidade de escolha, o que implica a negação da própria liberdade. A capacidade criativa e inventiva, inerente ao ser humano, cede lugar a um determinismo mecanicista, pelo qual a incorporação de modernas tecnologias leva inevitavelmente ao progresso. No caso da agricultura, esse pressuposto traduzse no aumento de produtividade e das possibilidades de lucros. Como o foco volta-se estritamente ao futuro, o passado e a tradição, enquanto tempos e espaços de construção de experiências, perdem sentido e função. Vive-se um período de euforia, mesmo que já evidenciando certa crise, em que os militantes neoliberais continuam atribuindo um poder mágico às tecnologias, considerando-as redentoras dos complexos problemas socioculturais, políticos e econômicos das sociedades.

Uma das críticas mais instigantes à compreensão de tempo linear e da história como realização inexorável do progresso foi elaborada por Walter Benjamin no texto "Sobre o conceito da história” (BENJAMIN, 1994, p. 222-232), escrito no início de 1940 num contexto extremamente difícil de perseguição nazista, da qual o próprio autor acabou sendo vítima. Na tese 9 (nove), Benjamin faz uma análise do quadro Angelus Novus, de Klee, em que o anjo da história esforça-se para olhar o passado, mas encontra muita resistência. Mesmo assim, consegue voltar-se ao passado e ver catástrofe e ruína enquanto o olhar hegemônico nota apenas progresso numa cadeia linear de acontecimentos. Para Benjamin (1994, p. 226), o anjo pretendia "acordar os mortos e juntar os fragmentos do passado”, porém uma tempestade impossibilitava olhar para o passado e o impelia a olhar para o futuro. Num esforço gigantesco, contrariando as tendências dominantes, o anjo consegue olhar para o passado e ver um “amontoado de ruínas crescendo até o céu”.

Benjamin defende a tese de que a noção de progresso fundamenta-se numa concepção de tempo "homogêneo e vazio", ou seja, um tempo que, ao abstrair as condições concretas da realidade, elimina os conflitos e as contradições. Assim sendo, o desenvolvimento da história não ocorre através de um mero encadeamento de fatos, como propugnam os dominantes. O determinismo transforma aquilo que é contingente em algo inexorável e, para tanto, escamoteia as 
contradições e os conflitos vividos por diferentes grupos e classes.

Benjamin continua sendo uma referência importante para uma leitura da história que ele denomina “a contrapelo". Enquanto as concepções lineares primam pela regularidade e pela permanência, uma leitura $a$ contrapelo busca dar visibilidade às práticas de barbárie e às contradições. Dessa forma, conclui Benjamin, "nunca houve um monumento da cultura que não fosse também um monumento de barbárie” (1994, p. 225).

Ainda, assinala Benjamin, a interpretação da história como um progresso continuum é própria daqueles que dominaram historicamente e que procuram descaracterizar experiências de luta e resistência, pautadas por temporalidades distintas daquelas que se tornaram hegemônicas. Daí o desafio proposto por Benjamin, de que "em cada época, é preciso arrancar a tradição do conformismo, que quer apoderar-se dela” (1994, p. 224). Para tanto, o historiador tem um papel privilegiado com vistas a despertar a esperança, "convencido de que também os mortos não estarão em segurança se o inimigo vencer. E esse inimigo não tem cessado de vencer” (1994, p. 224-225).

Tanto Walter Benjamin (1994) quanto Boaventura de Sousa Santos (2008a; 2008b) compreendem que o tempo linear é uma construção da classe dominante para legitimar as suas ações e intervenções históricas. Santos (2008a, p. 51) anota que a teoria do fim da história apregoada de modo mais intenso após a queda do muro de Berlin, em 1989, especialmente por Fukuyama (1992), "é o máximo de consciência possível de uma burguesia internacional que vê finalmente o tempo transformado na repetição automática e infinita do seu domínio". A linearidade e a repetição constituem-se em pilares desse discurso. "À medida que se foi construindo a vitória da burguesia, o espaço do presente como repetição (não como diversificação) foi-se ampliando, junto com a ideia de futuro entendido como progresso" (2008a, p. 52). Para Benjamin, a Social Democracia produziu "um conceito dogmático de progresso sem qualquer vínculo com a realidade" (1994, p. 229), de modo que não há como superar a concepção linear de tempo sem pensar numa teoria da história capaz de abarcar as diferentes, complexas e contraditórias temporalidades. Para Santos (2008a, p. 82),

[...] a teoria da história da modernidade é insustentável e que é, por isso, necessário substituí-la por outra que nos ajude a viver com dignidade este momento de perigo e a sobreviver-lhe pelo aprofundamento das energias emancipatórias.

Distintamente do autômato, referido por Benjamin, que conhece a história e suas determinações, o passado "traz consigo um índice misterioso, que o impele à redenção” (1994, p. 223). Esse índice misterioso, mesmo que na contramão dos interesses das classes dominantes, carrega a força de resistência e não deixa morrer as experiências que foram silenciadas. Dar visibilidade a essas experiências silenciadas, desacreditadas ou mesmo destruídas é condição para ampliar as possibilidades de intervir no tempo presente e projetar o futuro em outras bases. Segundo Benjamin, essa é a condição para a redenção do passado.

O problema está, portanto, na forma como foram sendo produzidas as representações sobre o passado e como elas são reproduzidas no presente para legitimar determinadas realidades. Para uma compreensão critica da concepção hegemônica de história e de tempo é fundamental evidenciar as contradições e os silenciamentos, o que implica pensar em novas opções e possibilidades. Mais do que isso, é imprescindível uma interpretação capaz de evidenciar as opções 
que foram feitas e as suas consequências, bem como as que foram relegadas ao silêncio. Em qualquer circunstância histórica, colocam-se possibilidades e os fatos resultam de opções feitas; caso contrário, reforça-se o determinismo segundo o qual o Homem deixa de ser sujeito para submeter-se às determinações externas. A redenção, a que se refere Benjamin, diz respeito às potencialidades e às possibilidades presentes na história e que, de alguma forma, foram excluídas. É nesses silêncios que reside a força revolucionária capaz de conduzir à emancipação. $\mathrm{O}$ passado não é um conjunto de imagens fixas, mas "um tempo saturado de agoras" (BENJAMIN, 1994, p. 229); ou seja, entrecruzam-se, em cada contexto, múltiplas temporalidades que precisam ganhar visibilidade, e isso depende da nossa capacidade de fazer explodir "o continuum da história”.

No texto "A queda do Angelus Novus: o fim da equação moderna entre raízes e opções”, Santos (2008a, p. 51-92) discute várias questões vinculadas ao tempo, tendo como eixo articulador a relação entre raízes e opções. Para o autor,

As raízes são entidades de grande escala. Como sucede na cartografia, cobrem vastos territórios simbólicos e longas durações históricas, mas não permitem cartografar em detalhe e sem ambiguidades as características do terreno. É, pois, um mapa que tanto orienta como desorienta. Ao contrário, as opções são entidades de pequena escala. Cobrem territórios confinados e durações curtas, mas fazem-no com o detalhe necessário para permitir calcular o risco da escolha entre opções alternativas (2008a, p. 54-55).

A modernidade, que se tornou hegemônica, radicalizou as opções em detrimento das raízes. Dessa forma, as escolhas recaíram sobre opções de curto prazo, ou seja, envolvem respostas imediatas sem as devidas preocupações com os impactos de longo prazo. Esse movimento foi fundamental para o desenvolvimento capitalista na medida em que este exige a aceleração nas intervenções e nos resultados de curto prazo, ao mesmo tempo em que foca o futuro como realização dos desejos imediatos a serem conquistados no tempo presente.

No texto "Uma sociologia das ausências e uma sociologia das emergências”, Santos (2008b, p. 93-135) elenca cinco modos da "produção de não existência”, entre os quais o da "monocultura do tempo linear”, e retoma a critica à concepção de tempo único e linear:
A história tem sentido e direção únicos e conhecidos. Esse sentido e direção têm sido formulados de diversas formas nos últimos duzentos anos: progresso, revo- lução, modernização, desenvolvimento, crescimento, globalização. Comum a todas estas formulações é a ideia de que o tempo é linear e que na frente do tem- po seguem os países centrais do sistema mundial e, com eles, os conhecimentos, as instituições e as formas de sociabilidade que neles dominam (2008b, p. 103).

Uma das preocupações de Boaventura de Sousa Santos é dar visibilidade às múltiplas temporalidades. Após a crítica aos cinco modos de produção da não existência, o autor faz um contraponto e elenca as "cinco ecologias", entre as quais a "ecologia das temporalidades”. Em continuidade, afirma que o tempo linear é uma entre muitas concepções de tempo que ganhou relevância no contexto da modernidade ocidental, mas convive com outras modalidades como o tempo circular, cíclico, glacial, eterno retorno etc.

Ainda, segundo Santos (2008b, p. 109), “as diferentes culturas e as práticas que elas fundam possuem regras distintas de 
tempo social e diferentes códigos temporais: a relação entre o passado, presente e o futuro; a forma como são definidos o cedo e o tarde, o curto e o longo prazo, o ciclo da vida e a urgência (...)”. Essas distintas compreensões de tempo incidem, diretamente, nos modos de organização da vida, do trabalho, do lazer etc. Max Weber (2003) já havia observado que o controle do tempo foi decisivo para o avanço capitalista e para a acumulação de capital, especialmente pela influência da ética protestante calvinista, a qual não fica adstrita ao religioso, mas está articulada com as organizações sociais e institucionais e com as práticas religiosas e culturais. Santos (2008b, p. 109) conclui que "a sociologia das ausências parte da ideia de que as sociedades são constituídas por diferentes tempos e temporalidades e de que diferentes culturas geram diferentes regras temporais”.

\section{As opções e os riscos segundo Ulrich Beck}

As reflexões de Ulrich Beck, na obra Sociedade de risco: rumo a outra modernidade, desafiam a pensar nas opções que foram e estão sendo feitas e nos riscos que elas representam para o presente e o futuro da humanidade. As contribuições de Beck justificam-se no presente texto porque pressupõem uma postura crítica frente à concepção linear de tempo. É importante recuperar, dos estudos de Beck, a ideia já discutida, segundo a qual, na sociedade de risco, “o passado deixa de ter a força determinante em relação ao presente. Em seu lugar, entra o futuro, algo todavia inexistente, construído e fictício como causa da vivência e da atuação presente” (2011, p. 40). O passado é um tempo de produção de riscos, ou seja, as suas raízes estão nas opções feitas no passado e no presente.
No início da referida obra, Beck ressalta que, na modernidade tardia, "a produção social da riqueza é acompanhada sistematicamente pela produção social de riscos" (2011, p. 23 - grifos do autor). O que ocorre é um expressivo desenvolvimento das forças produtivas humanas e tecnológicas, especialmente no contexto do grande projeto da revolução verde, que fez aumentar significativamente a produção pela mediação de tecnologias, de fertilizantes sintéticos e insumos químicos. Em conformidade com Beck (2011, p. 44), na Alemanha, o aumento no consumo de fertilizantes sintéticos cresceu de 134 para 378 kg/ha entre 1951 e 1983, e os insumos químicos de 25 para 35 mil toneladas entre 1975 e 1983, o que representa um incremento de $282 \%$ e $40 \%$, respectivamente.

Para Beck, "não se trata mais exclusivamente de uma utilização da natureza para liberar as pessoas de sujeições tradicionais, mas também e sobretudo de problemas decorrentes do próprio desenvolvimento técnico-econômico" (2011, p. 24). O que está em questão, portanto, não são apenas elementos periféricos e externos, mas o próprio modelo de desenvolvimento, especialmente pela iniciativa de países denominados desenvolvidos. Esse quadro fica ainda mais grave devido à ausência de um pensamento crítico. Em consonância com o autor:

O que surpreende nesse caso é o seguinte: o impacto ambiental da indústria e a destruição da natureza, que, com seus diversos efeitos sobre a saúde e a convivência das pessoas, surgem originalmente nas sociedades altamente desenvolvidas, são marcados por um déficit de pensamento social. Soma-se a esse déficit o grotesco: ninguém ${ }^{1}$ se dá conta dessa ausência -

\footnotetext{
${ }^{1}$ Beck é, por vezes, muito pessimista em relação às possibilidades de reversão do quadro de riscos que identifica e analisa. Isso fica evidente na afirmação
} 
sequer os próprios sociólogos (2011, p. 30 - grifos do autor).

Os limites de um pensamento crítico são a expressão da hegemonia da concepção linear de tempo que concebe a história como um movimento cumulativo de progresso e desenvolvimento. Por mais que a tese do fim da história tenha se revelado inconsistente, ainda guarda muito poder de convencimento. O pensar crítico não se constitui sem um olhar profundo do passado na busca por elementos que permitam estabelecer contrapontos. Esse olhar para o passado deve ter como mediação as grandes questões postas pelo tempo presente em relação aos problemas existentes e às possibilidades futuras. As descobertas e os avanços científicos nas últimas décadas estão contribuindo para um otimismo exagerado em relação ao futuro, caso em que, por exemplo, muitas das inovações não se perguntam pela sustentabilidade. Ao acreditar que os avanços científicos são infinitos e irreversíveis, fortaleceu-se um modelo que ofusca as contradições e os limites inerentes ao próprio modelo de desenvolvimento. Tratar de riscos implica, conforme Beck, assumir "um ponto de vista axiológico".

Constatações de risco baseiam-se em possibilidades matemáticas e interesses sociais, mesmo e justamente quando se revestem de certeza técnica. Ao ocuparem-se com riscos civilizacionais, as ciências sempre acabaram por abandonar sua

em que diz que ninguém se dá conta da gravidade. A expressão ninguém nega qualquer pensamento crítico, quando, na realidade, a criticidade coexiste com o pensamento hegemônico. Nesse sentido, a abordagem feita por Boaventura de Sousa Santos sobre temáticas similares consegue apreender as contradições, fazendo uma análise critica, mas, ao mesmo tempo, dando visibilidades às experiências alternativas em construção. Entre as obras que fazem referência mais diretamente ao tema em questão, podem-se ver as de Santos (2005; 2008b). base de lógica experimental, contraindo um casamento polígamo com a economia, a política e a ética - ou mais precisamente: elas convivem numa espécie de concubinato não declarado (2011, p. 35 - grifo do autor).

A capacidade crítica exige um esforço para contrapor-se ao hegemônico que ofusca nossos sentidos e impede ver determinadas circunstâncias e suas contradições. Um dos desafios, segundo Beck, é fundamentar uma crítica à ciência e seus pressupostos: "racionalidade científica sem racionalidade social fica vazia, racionalidade social sem racionalidade cientifica, cega” (2011, p. 36). Dentro dessa lógica, conclui o autor: "O efeito social das definições de risco não depende, portanto, de sua solidez científica” (2011, p. 38). Daí a necessidade de a ciência pensar-se não apenas em suas inovações, mas também nos resultados e nas consequências das suas descobertas, que devem estar articuladas a um projeto de sociedade com valores éticos e políticos explícitos. Quando todas essas dimensões forem contempladas, a responsabilidade pode ser partilhada. Caso contrário, fica difícil culpar todos pelos riscos reais ou potenciais.

Beck aponta que as opções feitas e que resultaram no modelo hegemônico vêm produzindo o que ele denomina "globalização dos riscos civilizacionais” (2011, p. 43-53). Diferentemente de outros períodos históricos em que os efeitos dos problemas criados recaiam fundamentalmente sobre os excluídos, habitantes das periferias de cidades ou países, os riscos globalizados produzem, dentro do seu alcance e entre as pessoas por eles afetadas, um efeito equalizador.

Nisto reside justamente sua nova força política. Nesse sentido, sociedade de risco simplesmente não são sociedades de classes; suas situações de ameaça não podem 
ser concebidas como situações de classe, da mesma forma como seus conflitos não podem ser concebidos como conflitos de classe (2011, p. 43).

A tese defendida por Beck é a de que os riscos que estamos vivendo não se limitam a um espaço ou a uma classe social, mas se estendem para o conjunto da sociedade. Para ele, há ameaças que podem ser generalizadas e "cedo ou tarde se atinge a unidade entre culpado e vítima" (2011, p. 45 - grifos do autor). Nesses casos, continua, suspendem-se as diferenças "entre pobre e rico, branco e preto, sul e norte, leste e oeste”. O estudioso conclui que "com a generalização dos riscos da modernização, é desencadeada uma dinâmica social que não mais pode ser abarcada e concebida em termos de classe" (2011, p. 47). O perigo global, como denomina, “já não respeita qualquer diferença ou fronteira social e nacional” (2011, p. 56). Essa tese, ao mesmo tempo em que põe em evidência a extensão dos problemas, pode ser questionada do ponto de vista social e econômico, levando-se em conta as diferentes condições e recursos disponíveis em caso de catástrofes. Quem depende de transporte público, por exemplo, para deslocar-se ao trabalho no trânsito caótico de grandes cidades, enfrenta situações bem mais adversas do que aqueles que utilizam helicópteros e outros meios de transporte. Nesse pequeno exemplo, todos são atingidos pelo mesmo problema, o trânsito, mas com intensidades diferentes e soluções distintas.

O próprio Beck reconhece que existem relações desiguais entre países capitalistas periféricos e centrais. Considera, ademais, que são os países do capitalismo central que transferem indústrias poluentes para os países pobres. Nesse caso, surgem desigualdades internacionais entre "países poluentes e aqueles que têm de arcar com o ônus da sujeira dos outros, com o aumento na taxa de mortalidade, desapropriações e desvalorizações” (2011, p. 48).

Com base em suas pesquisas, Beck conclui que a sociedade de riscos produz medos. "A solidariedade da carência é substituída pela solidariedade do medo. O modelo de sociedade de risco marca, nesse sentido, uma época social na qual a solidariedade por medo emerge e torna-se força política” (2011, p. 60 - grifos do autor). Em continuidade, o autor formula um conjunto de interrogações profundas que estão exigindo respostas:

Até onde chega a tenacidade da solidariedade do medo? Que motivações e forças de ação são liberadas? Como se comporta essa nova comunidade solidária dos medrosos? A força social do medo detona de fato o cálculo da utilidade individual? Em que medida estão abertas ao compromisso as amedrontadoras solidariedades surgidas da ameaça? Sob quais formas de atuação elas se organizam? O medo leva as pessoas ao irracionalismo, ao extremismo ao fanatismo? O medo não representou até o momento um fundamento de ação racional (BECK, 2011, p. 60).

O risco, de acordo com Beck (2011, p. 362), não significa catástrofe, mas a sua antecipação. "Risco é um conceito moderno, ele pressupõe decisões humanas, futuros humanamente produzidos (probabilidade, tecnologia, modernização)”. Na entrevista concedida a Arthur Bueno, que está em anexo da obra de Beck (2011, p. 361-376), o autor responde a interrogação do entrevistador: “o que há de novo na sociedade mundial de riscos?”

Minha tese é que as sociedades modernas e seus fundamentos foram abalados pela antecipação de catástrofes globais (mudança climática, crise financeira, terrorismo). Tais percepções dos riscos e 
incertezas globalmente fabricadas caracterizam-se por três aspectos. Primeiro, deslocalização: suas causas e consequências são, em princípio, incalculáveis; no fundo, trata-se de riscos hipotéticos ou virtuais que se baseiam especialmente em incógnitas cientificamente induzidas e dissensos normativos. Finalmente, não-compensabilidade: o sonho de segurança da modernidade europeia do século XIX se baseava na utopia científica de tornar os perigos de decisão e as consequências arriscadas cada vez mais controláveis; os acidentes podiam ocorrer na medida em que e porque eram considerados compensáveis. (BECK, 2011, p. 363 - grifos do autor).

Essa síntese expressa a complexidade de elementos que envolvem a sociedade de riscos. A crença num progresso infinito colide frontalmente com o autodesencantamento produzido pelos riscos globais. No entanto, segundo Beck,

a sociedade de risco é também uma oportunidade social. Contra a maioria das teorias sociais lineares, eu sustento que o sistema industrial, aparentemente independente e autônomo, transgrediu sua lógica e suas fronteiras e iniciou, assim, um processo de autodissolução ou autotransformação (2011, p. 369 - grifo do autor).

\section{Na contramão do discurso hegemô- nico: desafios para uma consciência crítica}

A fundamentação de uma postura crítica aos determinismos deve levar em conta os limites, mas também as potencialidades reais. Em todo o processo há contradições, o que nos força a construir um olhar crítico que não apenas aponte os limites em questão, mas também identifique as possibilidades. Santos (2008b) crítica a lógica da não existência “produtivista”, que assenta na monocultura dos critérios de produtividade capitalista. Nos termos dessa lógica, o crescimento econômico é um objetivo racional inquestionável e, como tal, é inquestionável o critério de produtividade que mais bem serve esse objetivo. Esse critério aplica-se tanto à natureza como ao trabalho humano (2008b, p. 104).

Ao propor a ecologia da produtividade como alternativa à produção da não existência, Santos trata da necessidade da

recuperação e valorização dos sistemas alternativos de produção, das organizações econômicas populares, das cooperativas operárias, das empresas autogeridas, da economia solidária, etc., que a ortodoxia produtivista capitalista ocultou ou descredibilizou (2008b, p. 113).

O livro Produzir para viver (SANTOS, 2005) é constituído por um conjunto expressivo de estudos realizados em diferentes países que evidenciam a existência de múltiplas experiências construídas em relação à produção e que apontam caminhos distintos daqueles propostos pelo modelo hegemônico. São alternativas de produção, de organização da produção, de cooperativas de trabalhadores e formas diferenciadas de comercialização. Mesmo que elas ainda não tenham conquistado uma posição mais expressiva em termos de visibilidade e de opção às formas de produção capitalista, não podem ser desprezadas. Na introdução geral da referida obra, Boaventura de Sousa Santos reconhece que "vivemos em uma época que a ideia de que não há alternativas ao capitalismo conseguiu um nível de aceitação que provavelmente não tem precedentes na história do capitalismo mundial” (2005, p. 24). Sem idolatrar as experiências em construção, é fundamental reconhecer que são elas que permitem fortalecer o pensamento crítico, na medida em que indicam para novas possibilidades. 
Para Santos (2005, p. 27-28), é importante fundamentar a crítica ao capitalismo em três dimensões: a) a produção de desigualdades de recursos e de poder; b) as relações de concorrência que fortalecem os interesses pessoais em detrimento da solidariedade; c) a exploração dos recursos naturais que ameaça as “condições físicas de vida na terra”. Esse terceiro tópico situa-se dentro das discussões feitas por Beck, para quem os riscos que estamos vivendo não são poucos e estão ampliando-se em várias direções, entre as quais o esgotamento de recursos naturais e a produção de poluentes que impactam sobremaneira na água e no ar. Cumpre acrescer, nesse sentido, que ainda é forte a mentalidade de que os recursos da natureza são infinitos. Contudo, somente em tempos de crise é que essas ideias podem ser mais bem avaliadas.

A exploração intensiva do solo no contexto do modelo de agricultura empresarial (agronegócio) não leva em conta os limites dos recursos naturais. A lógica que orienta essa forma de produção assenta-se num único critério, que é o lucro: custo versus rentabilidade. As demais questões dificilmente entram em pauta; nesse particular, Santos (2005, p. 64-74) discute nove teses sobre “alternativas de produção”. Na presente discussão, porém, serão destacadas três delas. A primeira sublinha que a produção alternativa não pode ser pensada apenas do ponto de vista econômico, visto que "seu potencial econômico emancipatório e as suas perspectivas de êxito dependem, em boa medida, da integração que consigam entre processos de transformação econômica e processos culturais, sociais e políticos” (2005, p. 64). Em outras palavras, é imprescindível uma avaliação global dos impactos produzidos pelas opções que estão sendo feitas para que a exploração intensiva dos recursos não se torne uma prática usual. Esse parece ser um dos principais problemas que estamos vivendo, atualmente, em relação à exploração intensiva do solo, da água, do petróleo etc. No que se refere à agricultura, os pressupostos hegemônicos resistem às criticas e justificam os meios utilizados para a produção em vista dos fins que se vinculam ao aumento da produtividade e do lucro. A rapidez com que são produzidas novas variedades de semente e novos produtos químicos para dessecar coberturas verdes, destruir ervas daninhas, combater fungos e insetos levanta uma indagação: até que ponto é possível acompanhar essa necessidade de inovação e quais os efeitos do uso intensivo desses produtos?

A quinta tese trata da relação entre democracia participativa e democracia econômica. "Uma das características emancipatórias das alternativas de produção não capitalista consiste no seu potencial para substituir a autocracia típica da produção capitalista - isto é, autoridade vertical que emana do patrão ou do manager - pela democracia participativa no interior das unidades de produção” (2005, p. 69 - grifos do autor). Experiências alternativas ao modelo hegemônico estão sendo construídas em diferentes espaços, potencialmente viáveis e sustentáveis, além de se constituírem em espaços importantes de exercício democrático. Enquanto a característica dominante da produção capitalista é a relação do indivíduo com a terra e o mercado, as experiências alternativas constroem espaços democráticos de decisão sobre o que produzir, as formas de comercialização e de consumo. Para a produção capitalista o fim é a lucratividade; na produção alternativa, por sua vez, entram em pauta outros elementos, entre os quais a participação e a sustentabilidade.

A sétima tese discutida por Santos trata das alternativas de conhecimento como possibilidade de novas opções de produção. O modelo capitalista hegemônico foi sendo 
constituído ao longo de séculos com a intervenção de muitos atores, especialmente de grandes corporações transnacionais que desenvolveram pesquisas e transformaram avanços científicos em tecnologias. A ciência moderna fortaleceu a lógica do tempo linear e também contribuiu para a consolidação do modo de produção capitalista (SANTOS, 1989; 2009, 2010a, 2010b). A consolidação de um modo de produção contra-hegemônico exige muito investimento em pesquisa e na produção de tecnologias alternativas tendo como fim uma produção de qualidade, sem desequilibrar o meio ambiente. Santos insiste na tese de que as experiências marginalizadas pelo modelo hegemônico têm muito a contribuir para o fortalecimento de opções tanto em relação aos conhecimentos quanto à produção. Essas mudanças, no entanto, exigem paciência, persistência e criatividade. “Os critérios para avaliar o êxito ou o fracasso das alternativas econômicas devem ser gradualistas e inclusivos” (2005, p. 72).

\section{Considerações finais}

As questões aqui discutidas suscitam um conjunto de interrogações que permanecem abertas. Não existem respostas simples para questões complexas, daí advém a necessidade de investigações que ajudem aprofundar as opções feitas historicamente e seus riscos, as possibilidades que foram excluídas e as experiências silenciadas. Isso implica formular uma crítica qualificada à noção de tempo linear concebido como única possibilidade que desemboca numa concepção de progresso focado essencialmente no futuro. O modo de produção capitalista que se desenvolve na agricultura apoia-se numa concepção de tempo que tem como lógica a exploração dos recursos naturais sem questionar as possibilidades futuras e os riscos embutidos nessas escolhas. Quando esses pressupostos são transformados em políticas agrícolas, predomina uma lógica pragmática e utilitarista segundo a qual o lucro justifica qualquer intervenção. Essa opção, que vem sendo feita há séculos, ganhou, nas últimas décadas, fortes impulsos em decorrência dos avanços tecnológicos e da expansão sem precedentes da indústria de produtos químicos. Que riscos que esse modelo provoca? São pertinentes as críticas feitas por Beck?

Uma segunda dimensão diz respeito ao reconhecimento da existência de múltiplas temporalidades e não de um tempo único, o que determina olhar para o passado e, dele, recuperar experiências, conhecimentos e saberes construídos, mas que foram relegados ao silêncio pelo modelo hegemônico. A ecologia de saberes, como se refere Santos (2008b), pressupõe a coexistência de muitos conhecimentos e saberes, para além dos reconhecidos pelo modelo hegemônico. No caso da agricultura, a diversidade de experiências deve estar no horizonte das possibilidades.

A agricultura num contexto de globalização precisa ser pensada como um todo, sendo que a construção de experiências alternativas exige um esforço coletivo e políticas de apoio à pesquisa numa perspectiva de produção sem riscos. A natureza não possui recursos infinitos, eles são limitados e, dependendo da intensidade com que são explorados, se esgotarão mais rapidamente. Assim sendo, é fundamental pensar em possibilidades de sobrevivência das sociedades e também da natureza. Nesse sentido, as diferentes ciências são desafiadas a dar conta de problemas que são complexos e fazem parte da sociedade como um todo.

Finalmente, é essencial pensar na mudança das consciências. O discurso da modernização e do progresso é sedutor e, por isso, conquistou uma posição hegemônica. 
A destruição dos recursos naturais, mesmo por pequenos agricultores, é justificada pela lógica do discurso hegemônico: aumentar a produção. A pergunta pela sustentabilidade do modelo de agricultura que explora os recursos naturais sem precedentes na história deve, pois, ser posta permanentemente. O desenvolvimento de um pensamento crítico coloca-se como possibilidade de que determinadas questões, que estão fora de pauta, passem a constituir questionamentos não apenas pelas ciências humanas e sociais, mas por todas as áreas de conhecimento, especialmente aquelas voltadas diretamente à produção agrícola.

\section{Referências}

ANDERSON, P. O fim da história: de Hegel a Fukuyama. Rio de Janeiro: Jorge Zahar Ed., 1992.

BECK, U. Sociedade de risco: rumo a uma outra modernidade. São Paulo: Editora 34, 2011.

BELMONTE, R. V. O país dos agrotóxicos. Jornal Extra Classe, Porto Alegre, abr., n.162, p. 7-8, 2012.

BENJAMIN, W. Sobre o conceito de história. In: BENJAMIN, W. Magia e técnica, arte e política. 7. ed. São Paulo: Brasiliense, 1994.

FUKUYAMA, F. O fim da história e o último homem. Rio de Janeiro: Rocco, 1992.

SANTOS, B. S. Introdução a uma ciência pós-moderna. Rio de Janeiro: Graal, 1989.

Produzir para viver: os caminhos da produção não capitalista. 2. ed. Rio de Janeiro: Civilização Brasileira, 2005.

A queda do Angelus Novus: o fim da equação moderna entre raízes e opções. In:
SANTOS, B. S. Gramática do tempo: para uma nova cultura política. 2. ed. São Paulo: Cortez, 2008a.

- Uma sociologia das ausências e uma sociologia das emergências. In: SANTOS, B. S. Gramática do tempo: para uma nova cultura política. 2. ed. São Paulo: Cortez, 2008b.

. Um discurso sobre as ciências. 7. ed. São Paulo: Cortez, 2010a.

. (Org.). Epistemologia do sul. São

Paulo: Cortez, 2010b.

WEBER, M. A ética protestante e o espírito do capitalismo. 2. ed. São Paulo: Pioneira, 2003. 